\title{
Öğretmenlerin Serbest Zaman İlgilenimlerinin Yaşam Doyumları Üzerindeki Etkisinin İncelenmesi
}

\author{
Investigation of The Effect of Teachers Leisure Time Attention on Life Satisfied \\ Ali ÇEVIKK ${ }^{1}$, Murat ÖZMADEN ${ }^{2}$, Efecan TEZCAN ${ }^{3}$, Gökhan DOKUZOĞLU ${ }^{4}$
}

\begin{abstract}
ÖZ
Çalışmada, Aydın il merkezinde görev yapan öğretmenlerin serbest zaman ilgilenimlerinin yaşam doyumları üzerindeki etkisinin incelenmesi amaçlanmıştır. Çalışma grubunu, 2020-2021 eğitimöğretim y1lı çerçevesinde ve Aydın il merkezindeki devlet kurumlarında görev yapan öğretmenler oluşturmuştur. Öğretmenlerin 115 'i kadın, 212'si de erkektir. Toplamda 327 öğretmen çalışmaya katılım sağlamıştır. Veri toplama aracı olarak, Diener ve diğerleri (1985) tarafından geliştirilen ve Yetim (1993) tarafindan Türkçeye uyarlanan "Yaşam Doyum Ölçeği" ve Kyle ve diğerleri (2007) tarafindan geliştirilen ve Gürbüz ve diğerleri (2018) tarafindan Türkçeye uyarlanan "Serbest Zaman İlgilenim Ölçeğì" kullanılmıştır. Ölçeklerin güvenirlik analizi sonucu: Serbest Zaman İlgilenim Ölçeği (SZIÖ) Cronbach's Alpha değeri, 92; Yaşam Doyum ölçeğinin (YDÖ) Cronbach's Alpha değeri, 85 olarak bulunmuştur. Öğretmenlerin serbest zaman ilgilenimlerinin yaşam doyumları üzerindeki etkisini belirlemek amaciyla yapısal eşitlik modeli (path) analizi uygulanmışıı ve serbest zaman ilgileniminin yaşam doyumu üzerindeki etkisi anlamlı ve pozitif yönlü bir etkisi olduğu görülmüştür $\quad(\beta=0.137, \quad \mathrm{p}<0.05)$. Serbest zaman ilgilenimindeki 1 birimlik artış yaşam doyum üzerinde 0.137 'lik artışa sebep olmaktadır. Yaşam doyumu üzerindeki değişimin \%0.019'ini açıklamaktadır $(\mathrm{R}=0.019)$. Sonuç olarak; öğretmenlerin serbest zaman ilgilenimleri yaşam doyumları üzerinde önemli bir etkiye sahiptir.
\end{abstract}

Anahtar Kelimeler: Öğretmen, Serbest Zaman, İlgilenim, Yaşam Doyumu.

\begin{abstract}
In this study, it is aimed to examine the effect of the leisure time interests of the teachers working in Aydin city center on their life satisfaction. The study group consisted of teachers working in public institutions in Aydın city center within the framework of the 2020-2021 academic year. Of the teachers, 115 are women and 212 are men. A total of 327 teachers participated in the study. As data collection tools, "Satisfaction with Life Scale" developed by Diener et al. (1985) and adapted to Turkish by Yetim (1993) and "Leisure Involvement Scale" developed by Kyle et al. (2007) and adapted into Turkish by Gürbüz et al. (2018) " used. As a result of the reliability analysis of the scales, the Leisure Involvement Scale (SCI) Cronbach's Alpha value was 92; The Cronbach's Alpha value of the Satisfaction with Life scale (LDS) was found to be 85 . Structural equation model (path) analysis was applied to determine the effect of teachers' leisure time involvement on life satisfaction and it was seen that leisure time involvement had a significant and positive effect on life satisfaction $(\beta=0.137, p<0.05)$. One unit increase in leisure time involvement causes an increase of 0.137 in life satisfaction. It explains $0.019 \%$ of the change in life satisfaction $\left(\mathrm{R}^{\wedge} 2=0.019\right)$. In conclusion; teachers leisure time involvement has a significant impact on their further life satisfaction.
\end{abstract}

Keywords: Teacher, Leisure Time, Interest, Life Satisfaction.

\footnotetext{
Etik Kurul No: 95674917-108.99-56174

${ }^{1}$ Arş. Gör, Ali ÇEVIKK, Spor Yönetimi, Marmara Üniversitesi Spor Yönetim Bilimleri ABD, ali.cevik@ marmara.edu.tr, ORCID:0000-00023664-6626

${ }^{2}$ Doç. Dr. Murat ÖZMADEN, Sporda Psikososyal Alan, Aydın Adnan Menderes Üniversitesi Antrenörlük Eğitimi, muratozmaden@gmail.com, ORCID:0000-0002-5913-6653

${ }^{3}$ Arş. Gör. Efecan TEZCAN, Sporda Psikososyal Alan, Gümüşhane Üniversitesi, Spor Yöneticiliği ABD, efecantezcan@ gmail.com, ORCID: 0000-0003-3284-6361

${ }^{4}$ Doktora Öğrencisi, Gökhan DOKUZOĞLU, Sporda Psikososyal Alan, Aydın Adnan Menderes Üniversitesi, Spor Bilimleri Fakültesi, dkzgkhn_1988@hotmail.com, ORCID: 0000-0001-5407-4927

İletişim / Corresponding Author: Efecan TEZCAN

Geliș Tarihi / Received: 10.02.2021

e-posta/e-mail:

efecantezcan@gmail.com

Kabul Tarihi/Accepted: 08.12.2021
} 
Zaman, kişiden kişiye farklı bakış açılarına göre anlam kazanan göreceli bir kavramdir. ${ }^{1}$ Serbest zaman ise bireysel ya da toplumsal etkileşimleri içeren rekreasyon etkinlikleri dâhil olmak üzere zamansal dilimleri oluşturan bir kavramdır. Birey, serbest zaman kavramı içerisinde; öz bakım, uyku, çalıştığı iş gibi alanların dışında kalan zorunlu olmayan bir faaliyetleri gerçekleştirmektedir. ${ }^{2}$ Serbest zaman stres, fiziksel ve zihinsel sağlığın korunması gibi kişinin olumsuzluklarla baş etmesine de yardımcı olmaktadır. ${ }^{3}$ Ayrıca kişinin sosyalleşmesine, yeni arkadaşlıklar kurulmasına, aile üyelerinin birbirleriyle iletişimlerinin güçlenmesine ve yaşamda mutluluk algısının geliştirilmesine de katkı sağlamaktadır. ${ }^{4}$ Eğitim-öğretim süreci, bireyin becerilerini ve yeteneklerini ortaya koyması için bir firsat sağlar. Bunun yanında; kişinin potansiyel özelliklerinin geliştirilmesinde de önemli bir rol oynamaktadır. Eğitim-öğretimin vazgeçilmez birer unsuru olan öğretmenlerin okul saatleri dışında kendilerine zaman ayırabilmeleri, sosyo-kültürel faaliyetlere katılmaları onları hem gündelik hayatta hem de iş hayatında rahatlamasına olanak sağlayacaktır. Günlük hayatın verdiği sikıntılardan kurtularak, zihinlerinde şekillendirdikleri amaçlarını gerçekleştirebilme, yeni şeyleri öğrenebilme ve yaşama dair üretim faaliyetlerini meydana getirerek varlığını hissettirebilmek bireyin yaşamdaki motivasyon gücünü artırmaktadır. $^{5}$ Öğretmenlerin serbest zamanlarında yaptıkları etkinlikler olumlu etkiler oluşturmaktadır. Bunlar; stresi

\section{GİRIS}

azaltma, öz güven sağlama, sosyal statü edinme ve yaşam mutluluğunun artmasıdır. ${ }^{6}$ Ayrıca, kişiye istendik bir yönde ruh hali kazandırmakta ve yaşama dair beklenti düzeyini karşılamaktadır. Yaşam doyumu ise bireyin yaşama duygusal tepkisi olarak yorumlanmakta; yaşam, iş, serbest zaman ve diğer çalışma dişı zamanlar olarak tanımlanmaktadır. ${ }^{7}$ Yaşam memnuniyeti, aile, okul ve arkadaşlar gibi alanlardaki genel yaşam kalitesinin bir değerlendirmesi olarak yorumlanmaktadır. ${ }^{8}$ Kişilerin yaşam doyumları olumlu ya da olumsuz birçok şeyden etkilenmektedir. Kişinin hayata yüklediği anlam, amaçlara ulaşmadaki hedefler, sosyal kimliği, fiziki ve ruhsal açıdan kendini sağlıklı görmesi, ekonomik düzeyi ve güvenliğinin sağlanması yaşam doyumunu etkileyen faktörlerden bazılarıdır. ${ }^{9}$ Yaşam doyumu üç kısımdan oluşur: kişinin kendi yaşamını diş standartlarla karş1laştırarak oluşturduğu mutluluk durumu, kendi yaşamını yargılayarak oluşturduğu duygu durumu ve günlük ilişkilerin ürettiği doyum durumudur. ${ }^{10}$ Öğretmenlerin mesleklerini yaparken yaşam doyumlarını etkileyen birçok unsurla karşılaşmaktadır. Öğretmenlerin beklentileri, pozisyonları, ekonomi boyutları, görev yaptıkları yerlerin içsel ve dışsal şartları yaşam doyumlarının şekillenmesinde önemli rol oynamaktadır. Ayrica kendilerine ve ailelerine zaman ayırabilmeleri, bu zamanları istediği şekilde geçirebilmeleri de yaşam doyumunu etkileyen unsurlardır. ${ }^{11}$ Buradan yola çıkarak çalışmamızda öğretmenlerin serbest zaman ilgilenimlerinin yaşam doyumları üzerindeki etkisinin incelenmesi amaçlanmıştır.

\section{MATERYAL VE METOT}

\section{Çalışmanın Modeli}

Genel tarama modeline göre yürütülen çalışmanın evrenini Aydın ilinin merkezinde yer alan ve devlet okullarında görev yapan öğretmenler oluşturmaktadır. Tarama modeli, mevcut durumu betimlemek için tasarlanmış bir araştırma yöntemidir. ${ }^{12}$

\section{Çalıșmanın Grubu}

Çalıșma grubunu, 2020-2021 eğitimöğretim yılı çerçevesinde ve Aydın il merkezindeki devlet kurumlarında görev yapan öğretmenler oluşturmuştur. Öğretmenlerin 115'i kadın, 212'si de erkektir. Toplamda 327 öğretmen çalışmaya katılım sağlamıştır. Çalışmanın verileri; Google Formlar aracılığı ile öğretmenlere 
ulaştırılmıştır ve gönüllülük esasına dayanarak yapmaları istenmiştir. Toplam olarak; 327 form analiz kapsamına dâhil edilmiştir.

\section{Verileri Toplama Aracı}

Çalışmada, araştırmacı tarafından oluşturulan demografik özellikler formu ile birlikte "Yaşam Doyum Ölçeği”" ve "Serbest Zaman İlgilenim Ölçeği” kullanılmıştır.

\section{Yaşam doyum ölçeği (YDÖ)}

İnsanların yaşam doyum düzeylerini belirlemeye yönelik ifadelerin yer aldığı Diener ve diğerleri (1985) ölçeği geliştirmiştir. Yetim (1993), Türkçeye uyarlayarak "Yaşam Doyum Ölçeğinin" oluşturmuştur. $\mathrm{Bu}$ ölçek, 5 madde şeklinde belirlenmiştir ve 7'li likert'in yapısı gereği; Kesinlikle Katılmiyorum- Kesinlikle Katılıyorum düzenindedir.

\section{Serbest zaman ilgilenim ölçeği (SZİ̈)}

Bireylerin serbest zaman ilgilenim düzeylerini belirlemeye yönelik ifadelerin yer aldığı ölçeği Kyle ve arkadaşları (2007) geliştirmiştir. ${ }^{13}$ Gürbüz ve arkadaşları (2018) Türkçeye çevirmiştir. Ölçekte 5 alt boyut vardır. Her alt boyutta 3 madde yer almaktadir. Toplamda 15 maddeden oluşmaktadır. 5'li likert yapısındaki ölçeğin ifadeleri; Hiç Katılmıyorum-Tamamen Katıliyorum düzenindedir.

\section{Verilerin Analizi}

Çalıșmanın verileri, AMOS 21,0 ve SPSS 25.0 programları kullanılarak analiz edilmiştir. Serbest zaman ilgileniminin yaşam doyumu üzerindeki etkisini belirlemek amacıyla Yapısal eşitlik modeli (path) analizi uygulanmıştır. Ölçeğin güvenirliliği Cronbach's Alpha katsayısı ile belirlenmiştir. Serbest Zaman İlgilenim Ölçeği (SZİÖ) Cronbach's Alpha değeri, 92; Yaşam Doyum ölçeğinin (YDÖ) Cronbach's Alpha değeri, 85 'tir.

\section{Araştırmanın Etik Yönü}

Araştırmanın gerçekleştirilebilmesi için Gümüşhane Üniversitesi Etik Kurul Başkanlığı'ndan 29.09.2021 tarihli E95674917-108.99-56174 nolu sayı ve 2021/6 numaralı belge ile gerekli etik kurul izni alındı. Çalışma hakkında öğretmenlere gerekli bilgilendirmeler yapıldı. Tüm denekler çalıșmaya gönüllü olarak katılmışlardır

\section{BULGULAR VE TARTIŞMA}

Tablo 1. Katılımcıların Tanımlayıcı Özelliklerinin Dağılımı

\begin{tabular}{|c|c|c|c|}
\hline Değişkenler & & $\mathbf{N}$ & $\%$ \\
\hline \multirow{6}{*}{ Yaş } & 30 yaş ve altı & 35 & 10,7 \\
\hline & 31-35 yaş & 91 & 27,8 \\
\hline & $36-40$ yaş & 115 & 35,2 \\
\hline & $41-45$ yaş & 52 & 15,9 \\
\hline & 46 yaş ve üstü & 34 & 10,4 \\
\hline & Toplam & 327 & 100 \\
\hline \multirow{3}{*}{ Cinsiyet } & Kadın & 115 & 35,2 \\
\hline & Erkek & 212 & 64,8 \\
\hline & Toplam & 327 & 100 \\
\hline \multirow{5}{*}{ Branş } & Resim, Müzik, Beden Eğitimi & 88 & 26,9 \\
\hline & Sinif & 78 & 23,9 \\
\hline & Sözel grup & 120 & 36,7 \\
\hline & Sayisal grup & 41 & 12,5 \\
\hline & Toplam & 327 & 100 \\
\hline \multirow{5}{*}{ Hizmet Y1lı } & 5 y1l ve altı & 34 & 10,4 \\
\hline & $6-10$ y1l & 111 & 33,9 \\
\hline & $11-15$ y1l & 89 & 27,2 \\
\hline & 16 y1l ve üstü & 93 & 28,4 \\
\hline & Toplam & 327 & 100 \\
\hline \multirow{4}{*}{ Eğitim Kademesi } & İlkokul & 72 & 22,0 \\
\hline & Ortaokul & 153 & 46,8 \\
\hline & Lise & 102 & 31,2 \\
\hline & Toplam & 327 & 100 \\
\hline
\end{tabular}


Tablo 1'e göre katılımcıların çoğu 36-40 yaş aralığındadır $(\% 35,2)$. Kendi kategorisinde en yüksek değişkenler sırasıyla cinsiyet değişkeninde erkek öğretmenler
$(\% 64,8)$, Branş değişkeninde sözel grup öğretmenler $(\% 36,7), 6-10$ yıllık hizmet yıl1 olanlar $(\% 33,9)$ ve ortaokulda çalışan öğretmenler $\quad(\% 46,8) \quad$ oluşturmaktadır.

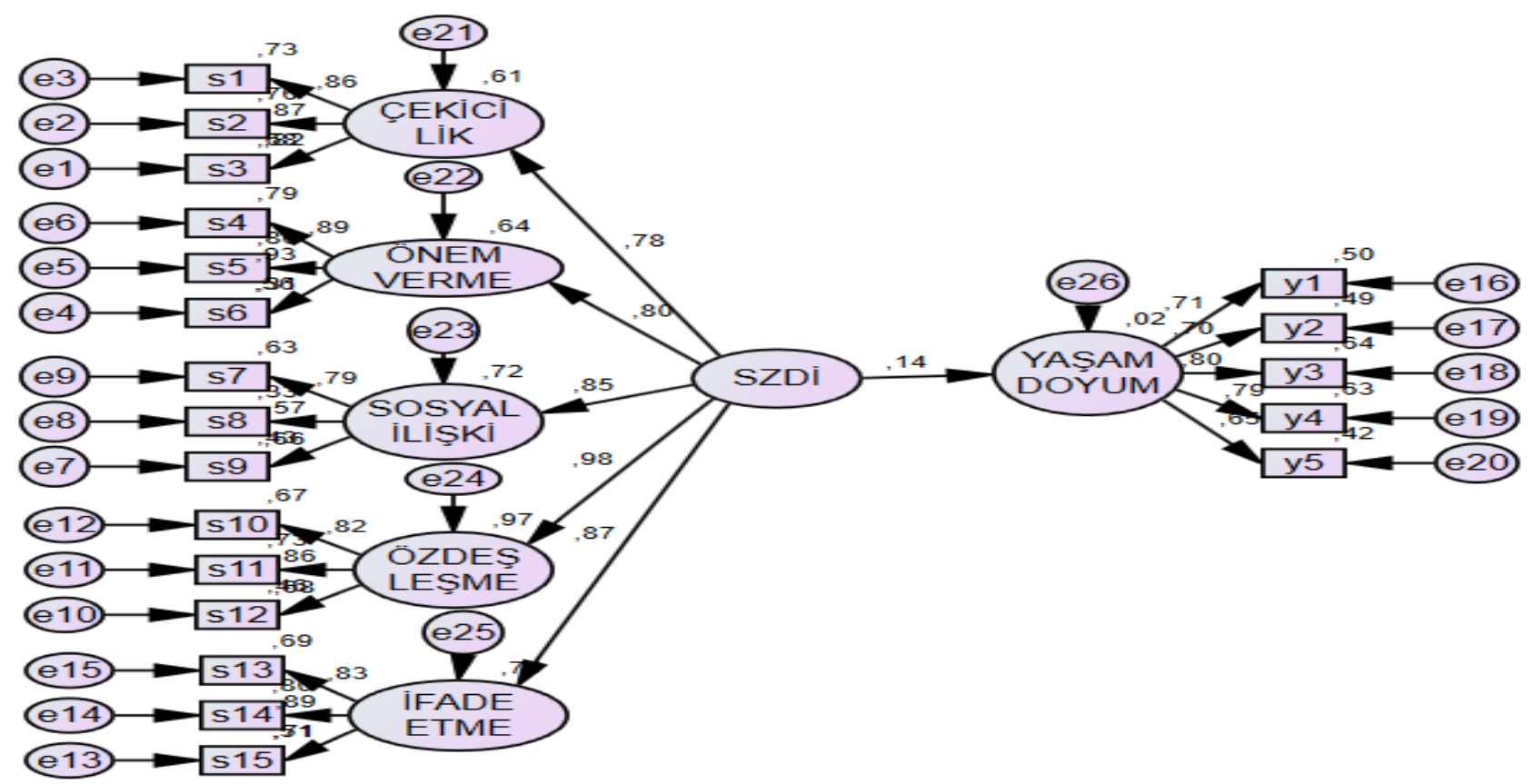

Şekil 1. Serbest Zaman İlgileniminin Yaşam Doyumu Üzerindeki Etkisini Belirlemek İçin Önerilen Modelin Path Diyagramı

Tablo 2. Araștırma Modeline İlișkin Analizler

\begin{tabular}{|c|c|c|c|c|c|}
\hline & Etki & Tahmin ( $\beta$ ) & Standart Hata & $\mathbf{t}$ & $\mathbf{p}$ \\
\hline \multirow{2}{*}{$\mathrm{D}$} & SZDİ $\rightarrow Y$. & 0.137 & ,142 & 2.163 & ,031 \\
\hline & \multicolumn{5}{|c|}{$\begin{array}{l}\text { Uyum İndeksleri: } \\
\text { : } 0.878 \text {, AGFI: } 0.844, \text { CFI:0.927 RMSEA: } 0.071\end{array}$} \\
\hline
\end{tabular}

Serbest zaman ilgileniminin yaşam doyumu üzerinde pozitif yönde anlamlı bir etkisi olduğu görülmektedir $(\beta=0.137, p=0,031)$.
Serbest zaman ilgilenimindeki 1 birimlik artış yaşam doyum üzerinde $0.137^{\prime}$ lik artışa sebep olmaktadır. Yaşam doyumu üzerindeki değişimin \%0.019'ini açıklamaktadır $\left(R^{2}=0.019\right)$.

\section{SONUÇ VE ÖNERÍLER}

Günümüz dünyasında bireyler, yaşamlarının devamını sağlayabilmesi için ihtiyaçlarını karşılamak zorundadır. $\mathrm{Bu}$ ihtiyaçları sağladıktan sonra kendilerine de vakit ayırması gerekmektedir. Kişilerin kendilerini daha iyi hissedebilmesi ve yaşam doyumunu arttırabilmesi için serbest zamanlarında yapılacak etkinliklere gereksinim duymaktadır. $\mathrm{Bu}$ çalışmada; Diener ve diğerleri (1985) tarafindan geliştirilen ve Yetim (1993) tarafından Türkçeye uyarlanan "Yaşam Doyum Ölçeği" kullanılmıştır. ${ }^{14,15}$ Kyle ve diğerleri (2007) tarafından geliştirilen ve Gürbüz ve diğerleri 
(2018) tarafından Türkçeye uyarlanan "Serbest Zaman İlgilenim Ölçeği" kullanılarak öğretmenlerin serbest zaman ilgilenimlerinin yaşam doyumları üzerindeki etkisi incelenmiştir. Öğretmenlerin serbest zaman ilgilenimlerinin yaşam doyumları üzerindeki etkisini belirlemek amaciyla yapısal eşitlik modeli (path) analizi uygulanmış ve serbest zaman ilgileniminin yaşam doyumu üzerindeki etkisi anlamlı ve pozitif yönde olduğu görülmüştür $(\beta=0.137$, $\mathrm{p}<0.05)$. Serbest zaman ilgilenimindeki 1 birimlik artış yaşam doyum üzerinde 0.137'lik artışa sebep olmaktadır. Yaşam doyumu üzerindeki değişimin \%0.019'ini açiklamaktadır $\left(R^{2}=0.019\right)$.

Alan yazıdaki çalışmalar incelendiğinde; Kocaer (2018), yaptığ eğitimi ve spor ögretmenlerinin serbest zaman ilgilenim düzeyi ile rekreasyon faaliyetlerine yönelik fayda düzeyinin beden eğitimi ve spor öğretmeni adaylarına göre daha yüksek olduğunu bulmuştur. ${ }^{16}$ Şeras (2017), çalışmasında serbest zaman etkinliklerine ilgilenimin arttırılması ile rekreasyon etkinliklerinden faydalanan katılımcıların başarı düzeylerine katkı sağlayacağı ve bununda sahip olunan serbest zaman süreleri ile doğrudan ilişkili olduğu sonucuna ulaşmıştır. ${ }^{17}$ Aydın ve Yaşartürk (2016), fitness merkezine katılım sağlayan bireyler üzerinde yaptıkları çalışmaya göre; haftalık kullanım sıklığı değişkenin, serbest zaman ilgilenim ölçeği alt boyutları üzerindeki etkisinin anlamlı olduğu, bu etkinin "çekicilik", "önem verme" ve "sosyal ilişki", alt boyut puanlarında olduğunu bulmuştur. ${ }^{18}$ Tüm alt boyutlarda ise; 5 gün ve üstü fitness merkezlerine giden kişilerin ilgilenim düzeylerinin daha yüksek olduğu sonucuna ulaşmıştır. Başka bir ifade ile kişilerin etkinlikler için geçirdikleri zaman arttıkça serbest zaman ilgilenim seviyeleri de artmaktadır. Gürbüz ve arkadaşları (2019), macera rekreasyonuna katılan bireyler üzerinde yaptıkları çalışmada; erkeklerin serbest zaman ilgilenim ortalama puanlarının kadınlara göre daha yüksek olduğu, fakat mutluluk düzeyinin ise daha düşük olduğunu bulmuşlardır. ${ }^{19}$ Ayrıca, etkinlik yılı değişkeninde uzun süreli olarak bu tür faaliyetlere katılım gösteren kişilerin diğerlerine göre serbest zaman ilgilenim ortalama puanlarının daha yüksek olduğunu tespit etmişlerdir. Bir etkinliğe veya faaliyete uzun süreli katılım sağlayan bireylerin yeni başlayan kişilere göre daha yüksek serbest zaman ilgilenim düzeyine sahip olması beklenen bir sonuçtur. ${ }^{20}$ Güldür (2020), yaptığı çalışmada ise; serbest zaman ilgilenim düzeylerinin elit hentbol sporcu benlik algısına doğrudan etki ettiğini bulmuştur. $^{21}$ Çünkü sporcuların serbest zaman aktivitelerinde yaptıkları etkinliklerin kişinin benlik algısıyla paralel bir şekilde ilerlediğini ve olumlu yönde etkilediğini söylemiştir. Pala ve Kolayiş (2016), çalışmalarında ise; beden eğitimi ve spor öğretmenlerinin serbest zaman tercihleri ile yaşları ve cinsiyetleri arasında istatistiksel açıdan anlamlı farklılıklar bulmuş ve yine beden eğitimi ve spor öğretmenlerinin serbest zaman tercihleri ile mesleki doyumları arasında istatistiksel olarak anlamlı farklılıklar bulmuştur. ${ }^{22}$ Beden eğitimi ve spor öğretmenlerinin serbest zaman etkinliklerinin mesleki doyumluluk düzeyi üzerinde etkiye sahip olduğu söylenebilir. Yönet (2018), lise öğrencilerine yapmış olduğu çalışmada; serbest zaman ilgileniminin yaşam kalitesi düzeyi üzerinde anlaml, pozitif yönde ve düşük düzeyde etkisi olduğunu tespit etmiştir. ${ }^{23}$ Serbest zaman ilgilenimlerinin genç bireylerin hayatlarında önemli bir etkiye sahip olduğu düşünülmektedir. Serbest zaman aktivitelerinin sosyal ilişkiler kurma, fiziksel, psikolojik ve sağl1k gibi unsurlar üzerinde olumlu etkilere sahip olduğu ifade edilmektedir. $^{24} \quad$ Yeşilyurt ve arkadaşları (2017), yaptıkları çalışmada; yetişkin bireyler üzerinde serbest zaman ilgilenim ölçeği ve iş doyumu ölçeği puanları arasındaki korelasyon katsayılarının pozitif yönde düşük, orta ve yüksek düzeylerde anlamlı bulmuştur. $^{25}$ Yüksek serbest zaman ilgileniminin katılımcılarda serbest zaman faydalarını ve yaşam kalitesini olumlu yönde etkilediğini, dolaylı olarak da iş doyumunu etkilediğini gösteren çalışmalar da mevcuttur. ${ }^{26}$ Emir (2020), kadinlar üzerine 
yaptı̆̆ı çalışmada; serbest zaman ilgilenim ölçeğinin alt boyutları ile serbest zaman doyum ölçeğinin alt boyutlar arasında düşük, orta ve pozitif düzeyde istatistiksel olarak anlamlı ilişkiler olduğu sonucuna ulaşılmıştır. ${ }^{27}$ Serbest zaman ilgileniminin doğrudan serbest zaman doyumu üzerinde etkisi olduğu söylenebilir. Yaşartürk ve ark. (2017), çalışmalarında; rekreatif etkinliklerde yer alan üniversite öğrencilerinin serbest zamanda algıladığı doyum düzeylerinin arttıkça yaşam doyumunun da artış gösterdiğini bulmuştur. ${ }^{28} \mathrm{Bu}$ tür etkinlikler içerisinde yer alan kişilerin serbest zamanlarını daha etkili ve verimli geçirdiği söylenebilir. Kılıç ve ark. (2016), yaz spor okullarına katılım sağlayan kişiler üzerinde yaptıkları çalışma ile; 'Yaşam Doyumu Ölçeği' ve 'Serbest Zaman Doyumu Ölçeği' alt faktörlerinden alınan puanlar arasındaki korelasyon katsayılarını pozitif yönde anlamlı bulmuştur. ${ }^{29}$ Bireylerin serbest zaman tatmin düzeylerinin, yaşam doyum düzeyleri arasında anlamlı bir ilişkiye sahip olduğunu göstermiştir.

Sonuç olarak; öğretmenlerin serbest zaman ilgilenimleri yaşam doyumları üzerinde önemli bir etkiye sahiptir. Çünkü bu tür faaliyetler içerisinde bulunmaları kişinin yaşantısında ve çevre ile olan ilişkilerinde olumlu gelişmeler sağlayacaktır. Literatürde yer alan bazı çalışmaların (Kocaer, 2018; Kolayiş, 2016; Yönet, 2018; Yaşartürk ve ark., 2017; Chin-Tsai, 2013) sonuçları araştırmamızın sonuçlarına benzer ve destekler niteliktedir. Çalışmanın daha geniş ve farklı örneklemler üzerinde uygulanması sonuçları değiştirebilir. $\mathrm{Bu}$ sonuçların literatüre çeşitli bakış açılarını kazandırabileceği de düşünülmektedir.

\section{KAYNAKLAR}

1. Beșikçi, T. (2020). Üniversite Kampüslerinde Rekreasyon Uygulamalarının Serbest Zaman Engelleri, Kolaylaștırıcıları ve Doyumu Üzerine Etkileri. Doktora Tezi, Manisa Celal Bayar Üniversitesi Sağlık Bilimleri Enstitüsü, Manisa

2. Jeong, E.H, Yoo, E.Y, Kim, J.B, Kim, J.R, Han, D.S. and Park, J.H. (2019). ''The Development of Leisure Participation Assessment Tool for the Elderly", Occupational Therapy International, 4, 5 .

3. Chang, Y.C, Yeh, T.M, Pai, F.Y. and Huang, T.P (2018). "'Sport Activity for Health! The Effects of Karate Participants' Involvement, Perceived Value, and Leisure Benefits on Recommendation İntention', International Journal of Environmental Research and Public Health, 15 (5), 953

4. Coleman, D. (1993). 'Leisure Based Social Support, Leisure Dispositions and Health'. Journal of Leisure research, 25(4), 350-361.

5. Asskın, C. (2016). "Öğretmenlerin Serbest Zaman Eğitimi ve Rekreasyon (Serbest Zamanda Yapilan Aktiviteler) Etkinliklerine Katılımlarındaki Sosyo, Ekonomik, Kültürel Etkenler-Düzce Örneği'’. Milli Eğitim Dergisi, 45 (209), 160-189.

6. Yoon, K. J. (2018). "'The Satisfaction of Leisure Activities of Pre-School Teachers on Teacher Efficancy and Teacher Satisfaction', The Korea Entertainment Industry Association Journal, 12 (6), 119-134.

7. Hong, S. M. and Giannakopoulos E. (1994). 'The Relationship of Satisfaction With Life to Personality Characteristics". The Journal of Psychology, 128 (5), 547-558.

8. Christopher, J.C. (1999). 'Situating Psychological WellBeing: Exploring The Cultural Roots of Its Theory and Research". Journal of Counseling and Development, 77(2), 141-153.
9. Schmitter, A.C. (2003). "Life Satisfaction in Centenarians Residing in Long-Term Care', http://www.mmhc.com/articles/NHM9912/cutillo.html (Erişim tarihi: 21.02.2003)

10. Serin, N.G. ve Özbulak, B. (2006). "Okul İdarecilerinin Duygusal Zekâ Beceri Düzeyleri İle Yaşam Doyumunu Yöneticilik Deneyimleri Ve Cinsiyet Açısından İncelenmesi”. Uluslararası Duygusal Zekâ ve İletişim Sempozyum Bildiri Kitab1 (ss.23-30). İzmir: Ege Üniversitesi, İletişim Fakültesi.

11. Boylu, A.Y. (2012). “Adalet Bakanlı̆̆ı'na Bağlı Kurumlarda Çalışan Personelin Yaşam Doyumu, İş Doyumu Ve Mesleki Tükenmişlik Düzeylerinin Cinsiyet Ve Hizmet Süresi Değișkenlerine Göre İncelenmesi"'. Adalet Dergisi, 44(6), 123.

12. Karasar, N. (2015). Bilimsel Araştırma Yöntemleri (28. basım). Ankara: Nobel Akademik Yayıncılık.

13. Kyle, G.T, Absher, J, Norman, W, Hammit. W. and Jodice, L. (2007). 'Modified involvement scale'. Leisure Studies, 26(4), 398-427

14. Diener, E.D, Emmons, R.A, Larsen, R.J. and Griffin, S. (1985). "The Satisfaction with Life Scale"'. Journal of Personality Assessment, 49(1), 71-75.

15. Yetim, Ü. (1993). 'Life Satisfaction: A Study Based on The Organization of Personal Projects'. Social Indicators Research, 29(3), 277-289.

16. Kocaer, G. (2018). Beden Eğitimi ve Spor Öğretmenleri ve Adaylarının Öğretmenlik Mesleğine Yönelik Tutum, Serbest Zaman İlgilenim ve Rekreasyon Faaliyetlerine Yönelik Fayda Düzeyleri Arasındaki İlișkinin İncelenmesi (Bartın İli Örneği). Yüksek Lisans Tezi. Bartın Üniversitesi, Eğitim Bilimleri Enstitüsü, Bartın. 
17. Seras, H. (2017). Gıda Tarım ve Hayvancılık Bakanlı̆ Çalışanlarının Katıldıkları Serbest Zaman Etkinliklerinden Tatmin Olma ve Algılanan Özgürlük Düzeylerinin İncelenmesi. Yüksek Lisans Tezi. Bartın Üniversitesi, Eğitim Bilimleri Enstitüsü, Bartın

18. Aydın, I. and Yasarturk F. (2016). "'Level of Involvement of Fitness Participants Towards Recrational Activities: The Status With Refence To Various Demographics of Them'. International Journal of Sport Culture and Science, 4 (Special Issue 3), 704-711.

19. Gürbüz, B, Güngörmüş, H.A, Aydın, İ. ve Çimen, Z. (2019). "Serbest Zaman İlgilenimi ve Mutluluk: Macera Rekreasyon Katılımcıları Örneği”. 2. Uluslararası Rekreasyon ve Spor Yönetimi Kongresi, 10-13 Mayis, 2019. Bodrum-Muğla

20. Dawson, J, Havitz, M. and Scott, D. (2011). 'Behaviora Adaptation of Alpine Skiers to Climate Change: Examining Activity İnvolvement and Place Loyalty", Journal of Travel and Tourism Marketting, 28(4), 388404.

21. Güldür, B.B. (2020). Hentbol Sporcularının Serbest Zaman İlgilenim ve Benlik Algısı Düzeyleri Arasındaki İlișki. Yüksek Lisans Tezi. Bartın Üniversitesi, Sosyal Bilimler Enstitüsü. Bartın

22. Pala, A. ve Kolayiș H. (2016). 'Beden Eğitimi ve Spor Öğretmenlerinin Boş Zaman Değerlendirme Alıșkanlıklarının ve Mesleki Doyumlarının İncelenmesi'. International Journal of Human Sciences, 13(1), 1887-1896.

23. Yönet, E. (2018). Lise Öğrencilerinin Sportif Serbest Zaman İlgilenim, Dijital Oyun Bağımlılığı ve Yașam Kalitesi Düzeylerinin Araştııılması. Doktora Tezi. Sakarya Üniversitesi. Sosyal Bilimler Enstitüsü, Sakarya.

24. Yau, M.K. and Packer, T.L. (2002). "Health and WellBeing through T'ai Chi: Perceptions of Older Adults in Hong Kong”. Leisure Studies, 21(2), 163-178.

25. Yesilyurt, O, Sahin, Y.A, Cakır, F. ve Kara, F.M. (2017) "Serbest Zaman Aktivitelerinin İş Doyumuna Etkisinin İncelenmesi”. 10. Spor Bilimleri Öğrenci Kongresi. 1012 Mayıs, Kirıkkale.

26. Chin-Tsai, K. (2013). "Leisure Involvement Leisure Benefits Quality of Life and Job Satisfaction". International Review of Management and Business Research, 2 (2), 421-428.

27. Emir, E. (2020). Serbest Zaman Doyumu, İlgilenimi ve Algılanan Özgürlük İlişkisi: Fiziksel Aktivite Yoluyla Kadınların Güclenmesi. Doktora Tezi. Hacettepe Üniversitesi, Sağlık Bilimleri Enstitüsü, Ankara.

28. Yaşartürk, F, Akyüz, H. ve Karatas, İ. (2017). "Rekreatif Etkinliklere Katılan Üniversite Ögrencilerinin Serbest Zamanda Sıkılma Algısı İle Yașam Doyum Düzeyleri Arasındaki İlişkinin İncelenmesi”. Uluslararası Kültürel ve Sosyal Araştırmalar Dergisi (UKSAD), 3 (Special Issue 2), 239-252.

29. Kılıç, S.K, Atasoy, K.L, Gürbüz, B. ve Öncü, E. (2016). "Rekreasyonel Tatmin ve Yaşam Doyumu Arasındaki İlişkinin İncelenmesi”. İstanbul Üniversitesi Spor Bilimleri Dergisi, 6 (3), 56-70. 